\title{
The Quest to Lead (with) Millennials in a VUCA-World: Bridging the Gap Between Generations
}

\author{
Johann Kornelsen
}

\begin{abstract}
Western workplaces are currently experiencing a leadership challenge that relates to a conflict between the senior leaders in organizations and the so-called Millennial generation. This has resulted in traditional leadership approaches being less effective in a "dynaxic" (dynamic and complex) world. The purpose of this chapter is to help senior leaders better understand the essence of the conflict between Millennials and the previous generations. It is an attempt to increase understanding of the conflict and solve the problem by suggesting a leadership approach that could work for both generations and help organizations survive in a VUCA world. After the nature of the conflict is described, a relatively new leadership approach—responsible leadership —is suggested, in combination with mentoring. Responsible leadership combines the essential qualities of three well known leadership styles: transformational, servant, and authentic. The transformational aspect of responsible leadership relates to encouraging teamwork, setting high performance targets, and encouraging out-of-the-box thinking among followers. As servants, responsible leaders put the interests of subordinates and organizations first to create an empowering experience for followers. An authentic leadership approaches ensures learning agility, flexibility, and the participation of others. Through mentoring, Millennials may come to identify with their mentees and even adopt some of their values and attitudes. So-called reverse mentoring may provide a very valuable double function: increasing Millennials' involvement within their organizations while at the same time engaging and educating Baby Boomers.
\end{abstract}

Leadership is typically influenced by three component factors which are leader, follower, and context (Yukl 2013). Effective leadership is displayed when these three dimensions are appropriately aligned. Currently, the Western world is experiencing two challenges in the context of this triangle: the first one concerns leader-follower work relationships and the other arises from current challenges in the environment of the corporate world. One central challenge is the conflict between

\footnotetext{
J. Kornelsen $(\triangle)$

Regent University, Virginia Beach, VA, USA

e-mail: johann@kornelsen.biz
} 
senior leaders in organizations and the so-called Millennials, the emerging leader generation born between 1980 and 2000. This cohort, known as Generation Y, will account for $50 \%$ of the global workforce, and will outnumber their Generation X predecessors quite quickly (PwC 2011). For many employers and senior leaders, Generation Y presents a leadership challenge. The concerns and criticisms of parents and leaders stretch from a claim that this generation is dumber than previous generations, to the assertion that it is narcissistic or has no work ethics (Tapscott 2009). Gelbart and Komninos (2012) argue convincingly that workforce managers always struggle with new generations and their different world views and values, and Gesell states that the current generational mix of Baby Boomers, Gen X, and Gen Y makes leadership more complex. The large difference between the generations results in traditional leadership approaches being less effective. Acknowledging this, authors such as Ferri-Reed suggest that contemporary employers need a transition "from a 'boomer-centric' workplace to a 'millennial-centric' workplace" (Ferri-Reed 2014, p. 13). As Kilber concludes, the conflict between the generations needs to be solved through embracing the different approaches that come with the new generation. Such an attitude will get the most out of this new generation for the benefit of the organization (Kilber et al. 2014). Even if senior leaders find a leadership approach that fits the needs of the Millennials, the organizational environment still poses further challenges. Therefore, a leadership approach aimed at making Millennials more effective is not enough: the approach applied must also address the challenges of the environment. Currently, the term most frequently used to describe organizational environment is VUCA. The acronym VUCA, originally coined by the US Army, refers to an environment that is volatile, uncertain, complex, and ambiguous. Since all of these characterize our corporate world today, traditional approaches to leading organizations no longer work (Nick Horney et al. 2010). The combination of these two leadership challenges [Millennials changing the way that relationships are formed, and therefore how work is carried out and knowledge transferred (Rodriguez and Rodriguez 2015), and the prevailing characteristics of the VUCA world] demands enormous wisdom and a completely new leadership approach. This applies especially to senior leaders in contemporary organizations. The purpose of this chapter is to help senior leaders better understand the essence of the conflict between Millennials and the previous generations, and to explore the challenges that the current organizational environment poses for organizations. Its ultimate purpose is to determine whether there is a leadership approach that can help lead Millennials more effectively and can support organizations in facing a "dynaxic" (dynamic and complex) world. 


\section{The Conflict Between Generations}

To understand the conflict between senior leaders and Millennials we need to understand the world views and values of the Millennial generation. Pinzaru et al. suggest that the theory regarding the difference in generations is based on the idea of cohorts. A generation is a group of people going through similar experiences in a certain period of time. External forces, including "media, economic and social events, popular culture, values shared by families and friends and used as guidance in action," shape a generation and create unique sets of values (Pinzaru et al. 2016). In this context, a generation may be seen as an "approximation of the collective set of attitudes, behaviors, ideals, memories, and life expectations that will certainly affect work-life" (De Campo et al. 2011). The so-called Baby Boomers (born between 1946 and 1964), Generation X (1965-1980), and the Millennials are the three generations currently in the workplace. The term that is also used for the Millennials is Generation Y, where the "Y" comes from the English word youth, representing the first wave of a digital generation, born into a world of technology. Being aware that every attempt at delineating the characteristics of any generation will be open to debate, Rodriguez and Rodriguez have summarized the most important characteristics of Millennials to help senior leaders understand and lead this generation better. They are (Rodriguez and Rodriguez 2015, pp. 856-857):

- Tech-savvy: Millennials are familiar with technology and use it as a key method for knowledge transfer in organizations.

- Informed: Since all kind of information is available for this generation at any time from the internet or social networks, this generation believes that they must be heard. This may lead to them being over-confident in their own abilities.

- Diverse: Millennials are tolerant to diversity and put a high value on teamwork in a collaborative, informal context.

- Multitaskers: Millennials perform tasks simultaneously, believing that they excel at this.

- Autonomous: Millennials tend to have less respect for hierarchies, especially if actions are not well structured.

In general, this generation prefers to sacrifice high incomes for leisure time.

It also believes that education is the key to success and is considered the besteducated generation ever, especially with regard to the demands of a globalized world (Kilber et al. 2014). Millennials want to learn, develop their potential, and do meaningful work (Müller 2013). Buying into the mission of an organization is also important for this generation, considering great benefits and state-of-the-art technology as important factors for an ideal work environment (Christensen 2017). In general, they value personal relationships in private and professional contexts (Balda and Mora 2011). Optimism, civic duty, confidence, and achievement are considered to be the core values of this generation (Al-Asfour and Lettau 2014).

While Millennials have many strengths, there are also traits that are considered weaknesses or seen as negative from the perspective of other generations. There are 
some terms that are used in discourse about Gen Y (Rodriguez and Rodriguez 2015, pp. 857-858):

- Plaintiffs Reward for activities rather than for achievements is an expectation. Immediate gratification is often demanded, while commitment can be very shallow.

- Lightning Speed: This generation has no tolerance for delays and expects feedback, results, promotions, and much else as soon as possible.

- Over-watched: Since many Millennials were planned from birth, their parents expect them to achieve a lot of (their parents') goals. Many individuals from this generation have not learned to set their own goals and pursue them with discipline. They expect others to set the goals for them and to explain why things must be done. This may also result in high dependency on their parents, even after reaching adulthood.

- Grasshoppers: Like grasshoppers, Millennials stay with groups and organizations for a relatively short time. They move because staying still could mean losing other opportunities. Thus, they are skeptical of long-term commitment.

- Sailboats: While Millennials complete multiple tasks at the same time and process large amounts of information by using the newest technology, they reveal a lack of profundity in knowledge and synthesis. Therefore, their critical thinking is sometimes questioned.

- Fragile: The ability to recover from setbacks and failures is less pronounced than in previous generations. While Millennials may be adept at creating and managing the impression they want to give, and also at getting jobs, they are not very good at keeping jobs or maintaining relationships.

Millennials are sometimes considered to be naïve and not prepared for the world of work (Pinzaru et al. 2016). At the same time, they are overly self-confident. According to Hines, Millennials are "ready to lead now and are confident in their ability to make things happen and change the world" (Hines 2011). This leads to the paradoxical combination of self-trust and dependency on others at the same time (Pinzaru et al. 2016). Pinzaru even considers narcissism to be the central characteristic of this generation. Gen Y members want the organizations they work with to offer them many opportunities but "they want things to develop only as they wish and they have a sense of entitlement, which is obvious in their demands." Leading Millennials is therefore a challenge because of their strong drive to succeed while wanting little supervision and guidance (Hines 2011). Since almost all information is available for Millennials at any time, they no longer have a need for senior leaders as content experts, weakening the influence and authority of those leaders. Flat hierarchies are taken for granted, resulting in free-flowing and bidirectional communication regardless of position (Balda and Mora 2011).

In order to understand the conflicts between the generations, we need to have a summary understanding of the different values and world views that distinguish the cohorts. Baby Boomers are very often seen as competitors who have dedicated their lives to their jobs (DelCampo et al. 2011). For researchers, it is therefore not clear which stance this generation really takes on teamwork (Bencsik et al. 2016). Many 
have developed career ambitions and, where they are parents, this has given rise to personal struggles and to an increase in the divorce rate. While being idealistic, this generation did not have the necessary free time to achieve the many goals they had set for themselves (DelCampo et al. 2011). In terms of relationships and communication, this generation puts personal communication first (Bencsik et al. 2016). The Boomers' main goal is a stable existence, realized through conscious, long-term career building. The main traits of this generation are patience, soft-skills, respect for traditions, and hard work (Ibid.). Bencsik et al. add that this generation accepts and uses hierarchies to lead. More negative characteristics could be exaggerated modesty or arrogant inflexibility, passivity, cynicism, or disappointment (Ibid.).

Naturally, the values and world views of the Boomers as outlined here may collide with the preferences of the Millennials in many organizational contexts. While Generation $\mathrm{Y}$ is skeptical of hierarchies, Boomers rely on them and expect people to accept the flow of authority and information according to defined hierarchies. In that context, Generation Y believes strongly in an eye level communication, common effort, and teamwork that is independent of hierarchies. Boomers might feel less respected, and even offended, by that attitude on the part of the younger generation, especially, if it is bolstered by strong self-confidence in a relatively inexperienced person. Ferri-Reed notes that "Millennials respond best when communication is direct, honest, and without hidden agendas. The quickest way to lose the loyalty of Millennials is to withhold information or restrict it to a selected few individuals" (Ferri-Reed 2014, p. 16). There is yet another area of conflict related to the work ethic because Boomers believe that those who openly display strenuous effort and spend more time at the office actually possess a stronger work ethic. This may be the reason for Millennials reporting that their own work styles do not seem to fit within the effort-focused paradigm of work ethics. In general, Millennials are more result than effort oriented. Boomer managers sometimes express the view that Millennials want the honors of the workplace without making the sacrifices that earn them, the same sacrifices that the Boomers made in order to achieve their goals. Therefore, while Boomers rely on patience, effort, and position-based authority, the Millennials question these values. Nevertheless, it must be admitted that the desire for independence, when combined with a lack of respect for tradition, and occasional arrogance, is not something to be proud of. This conflict, then, is a result of different world views and lack of appreciation and understanding of each other. Where there is an inflated self-esteem on the Gen Y side, there is also a rigid, closed-minded, overbearing attitude on the Boomer side. This rigidness, and unwillingness to take the discussion further, produces an inability to cope. HR expert Linda Gravett describes her experience with some Boomers as follows: "Many boomers are not coping well. I've had so many boomers say to me, I'm not going to learn how to text, I want to talk to someone face-to-face, doggone it, and I'm going to track them down till I find them faceto-face" (Huffington Post 2011). The consultant suggests to that generation that if they want to communicate with people of all age groups they will need to learn how to text and how to use instant message, instead of demanding face-to-face communication as often as possible (Ibid.). In a poll conducted by the Society for Human Resource Management (SHRM), 47\% of younger workers complained that senior managers were resistant to change and had a tendency to micromanage, something that Gen Y 
does not like at all (Huffington Post 2011). This creates another area of conflict, because Gen $\mathrm{Y}$ is open-minded, accepting of diversity, and unafraid of change. What this generation obviously demands are leaders acting as coaches instead of bosses. But while there are conflicts and opposing world views, there is also common ground that may help to bring the generations together and increase understanding and appreciation. As Anderson et al. conclude, Millennials and Boomers are similar in the way they see work. Both generations value meaningful and challenging work.

The relationship between Gen $\mathrm{X}$ and Gen $\mathrm{Y}$ is different, and seemingly less conflictual. According to Lissitsa and Kol, many members of the Gen X generation grew up when both parents were working or in divorced households. As a result, Gen $\mathrm{X}$ members seem to be more independent than the average Millennial (Lissitsa and Kol 2016). The childhood background they describe may also result in insecurity and a minimal sense of tradition. This generation may lack the social skills of its parents, but it was the first generation to develop stronger technical skills (Ibid.), giving them a connection to the tech-savvy Millennial generation. It may even be stated that in terms of multiculturalism and global thinking, Gen X was a forerunner (Ibid.). Here, again, we can see Gen $\mathrm{X}$ as a transition generation and a link between the Boomers and Gen Y. Regarding relationships, Gen X prefers a mixture of personal and virtual communication (Bencsik et al. 2016). While this generation shows openness to diversity and is curious about new ideas, it still values hard work. This generation is known for its practical approach to getting things done very quickly, effectively, and efficiently (Lissitsa and Kol 2016). But, as is the case with every generation, Gen $\mathrm{X}$ has its negative aspects. From time to time this generation can be materialistic and can choose to abide by the rules. What unites it with Gen Y is having less respect for hierarchy than the Boomers. Nevertheless, it tends to abide by the rules (Bencsik et al. 2016). To conclude, it is not surprising that there is much more literature on the conflict between Gen Y and Baby Boomers than about the relationship between Gen Y and Gen X. The characteristics mentioned show that Gen $\mathrm{X}$ is most likely to get along with the other generations at the workplace. Having appreciated the nature of the conflict between Baby Boomers and Millennials, especially, it is in this context that we should observe the current VUCA environment with its challenges, and its risks of generational conflict.

\section{The VUCA World and Its Challenges}

The term VUCA was developed by the US Army War college to describe the current world, being volatile, uncertain, complex, and ambiguous (Horney et al. 2010). Volatility stands for the speed, magnitude, and dynamics of change, while uncertainty describes the unpredictability of issues and events. Complexity stands for the chaos that surrounds all organizations, and ambiguity describes "haziness of reality and the mixed meanings of conditions" (Ibid.). Rodriguez and Rodriguez show that contemporary organizations must face both sudden and continuous change all the time. For instance, Millennials do not remain in one workplace for more than a few 
years, because someone who stayed too long would be considered a failure. According to the authors, in such a world, most decisions seem to be based on emotion instead of reason (Rodriguez and Rodriguez 2015). Further, the uncertainty of the future makes personal and organizational identities fluid and the "ethical radar" is used to make decisions. The complexity in our world produces confusion. Even when all routes seem to be equally valid, the result is even greater confusion and perplexity (Ibid.). Finally, in an ambiguous world, "every decision taken presents a series of ambiguous dilemmas" and affects both the individual's ethics and organizational core values (Ibid.).

According to Sarkar critical factors for success in a VUCA world are as follows (Sarkar 2016):

- Sound business fundamentals;

- Innovation;

- Fast-paced response;

- Flexibility;

- Change management;

- Managing diversity at local and global level;

- Market intelligence; and

- Strong collaboration with all relevant stakeholders including employees, customers, suppliers, shareholders, and society.

Horney et al. emphasize the aspect of strong collaboration in the context of organizations (Horney et al. 2010). As the authors argue, the leadership challenge of the current phase is to balance relationship management and task achievement. Leaders will need to deploy user-friendly technology to involve people from different parts of the world, and from different generations, in sharing knowledge and information. Agile, successful leaders of the future need to learn how to infuse collaboration into work processes, job roles and monitoring, and rewards and development systems, thus generating changes in mindsets and behavior (Ibid.). Difficult VUCA times demand shared effort and collaboration between generations because in an ambiguous world, where single leaders sometimes seem to be overwhelmed, collective effort in heterogeneous groups is needed for wise decision making. Millennials are willing to make collaborative decisions, but if vanity on both sides leads to a stand off because of generational differences, appropriate decision making cannot happen. Today's leaders need strong discernment, which may be defined as the "ability to regulate one's thinking in the acquisition and application of knowledge to make decisions that are right, fair, and just" (Traüffer 2008, p. iii). Excellent discernment in a VUCA world is a result of joint decision making in heterogeneous teams. One crucial factor for organizational survival and success is, therefore, successful collaboration, especially between Baby Boomers and Millennials. The future of organizations in a VUCA world is related to whether these two generations can resolve their conflict and get on with shared leadership. 


\section{Interim Conclusion and Solution Finding}

Further reflection on the facts sheds more light on the nature of the conflict. Some may ask why the experienced and so far successful Baby Boomer generation should change their approach and adapt to the needs of the Millennials. It seems the arguments for adapting to the ways of this generation are strong. In a recent opinion poll, $62 \%$ of 186 German high-level managers said they believed that in the next year, young leaders would climb the career ladder faster than older generations (Jumpertz 2017). The Millennials have the appropriate attitudes and skills for success in the new world of VUCA: there is an openness to change, to taking risks, a willingness for collaboration, and a strong confidence that they can achieve success. While sounding almost arrogant, the Millennials are the best educated generation so far, and operate in a more developed international context than either of the previous generations. As Bishop states, they "possess skills, knowledge, and abilities that far exceed those of previous generations" (Bishop 2014, p. 54). Last but not least, their tech-savviness is of enormous help to them in dealing with the challenges of a digitalized world. The fit of Gen Y's strengths with the characteristics of the new world is the strongest argument for relying on that generation. The world is changing so fast that many of the experiences and skills of the previous generations are no longer an asset. Many senior leaders in German small and medium enterprises (SMEs) are unable to estimate the consequences of digitalization on their companies. In addition, they do not have a positive approach in facing an uncertain future. In Germany, we can see that defensiveness is an attitude that tends to intensify blindness when it comes to dramatic change. Germans tend to be more pessimistic about the future and have an external locus of control. Even the media displays a disparaging reaction to trends from the US, especially from Silicon Valley (Keese 2016). The challenges of digitalization confront a world view where things need to be controlled and in which well-tried Christian working values, including diligence, persistence, and fidelity are sufficient. This is not enough in times of digitalization, where the rules of the game have changed and where the upcoming wave will destroy formerly successful traditional businesses. On the other hand, we have shown that Millennials are not easy to lead and that they display some negative attitudes, including naivety and exaggerated self-confidence. While corrective feedback is often required, it can cause Millennials to become defensive because they see receiving praise as a birthright (Hall 2016). Further, the tendency of Gen Y members to switch organizations frequently creates a further challenge for their leaders. All in all, it is not surprising that conflict flares up especially between Baby Boomers, who stand for reliability and patience, and Gen Y.

Baby Boomers typically react to conflict in two ways: they either devalue Gen Y to inflate their own significance, or they exaggerate their praise of the generation. Swaim provides an example of the former in a discussion of leading US Millennials (Swaim 2016). The author tries to show exhaustively that in terms of literacy and numeracy skills, Millennials are less skilled than previous generations. Further, he tries to show that their general knowledge of history, and of other subjects that 
Swaim deems important, is generally inadequate. He also cites the tendency of Gen $\mathrm{Y}$ to marry later, or to live with their parents longer than previous generations did. Swaim finishes by stating that there is no need for "Millennial experts" to tell the world how to lead Millennials because our current organizational needs are not really different from before and what we need is simply one consistent leadership style for all generations in the workplace (Ibid.).

The alternative view is put forward by Smith in the preface to a book about the Millennials (DelCampo et al. 2011, pp. Xv-Xvi):

The Millennials have expertise and knowledge that we do not-for example, they understand technology and use it like no other appendage. They are not afraid of new ideas. They have grown up with diversity in their classrooms and their activities, and they welcome it now. They are quick to laugh and quick to critique, not automatically accepting the status quo as the only way to get things done. Yes, they demand a lot, but look what they have accomplished in their short lives. (...) The Millennials are poised to become our greatest generation yet. They work together. They embrace groups and collaborate. They are forward-thinking, positive, and achieve what they set their sights on. As the authors aptly attest, the Millennials are the heroes of the workplace today.

Both stances are most likely extremes. While Swaim fails-does he even want to try? - to integrate the VUCA environment into his considerations, Smith virtually glorifies Gen Y. Nevertheless, Swaim represents a significant portion of the Baby Boomers who display a kind of ignorance and arrogant inflexibility, cynicism, and perhaps even disappointment. Their anger may be a result of frustration: some Baby Boomers unconsciously feel overly challenged or no longer respected. And here is the contribution of the younger generation that-in its exaggerated self-confidence-does not see the strengths of the older generation. Their respective vanities, and the conflicting negative emotions involved, endanger organizations because they impact greatly on decision making. As Goleman has shown, positive moods often lead to better decisions by individuals and teams. Distress, instead, erodes mental abilities. Effective leaders have learned to understand their own emotions and are able to control negative ones. However, they can speak openly about their emotions and are even able to "attune to a wide range of emotional signals" in a person or group (Goleman et al. 2004, pp. 253-256). In a VUCA world, where joint decision making is key, the unsolved conflicts and the negative emotions involved are a threat to organizations. Therefore, while some Baby Boomer leaders may doubt whether they have something to offer, Millennials should recognize that this generation does have strengths and should honor these strengths in order to build well-rounded teams for the benefit of their organization. Millennials need to understand that their passion for meaningful work gives them a real connection with Baby Boomers, who may also provide role-models in terms of work ethic and workplace commitment. Senior leaders will have experienced many storms and will have gained a great deal of experience in dealing personally with difficult times, changes, conflicts, and organizational politics. Millennials need to understand that their own drive and their own 
skills can be made more effective when used in conjunction with the wisdom of seniority.

The goal of this chapter is to present a leadership approach that may be helpful to those facing a complex business environment and it may help to connect senior leaders and Millennials for the benefit of their organizations. The suggestion is to adopt a relatively new leadership approach—responsible leadership-in combination with mentoring. Responsible leadership helps to meet the demands of followers and their organizations, while mentoring, as will be demonstrated, is helpful for strengthening the ties between senior leaders and Millennials.

\section{Responsible Leadership as Part of a Solution}

As already demonstrated, the VUCA world demands a particular style of leadership-agile leadership that fosters collaboration and unbiased communication between generations. This kind of collaborative leadership allows organizations to be more innovative, flexible, and fluid, and enables them to make sound decisions in an ambiguous world. In addition, the Millennials' preferred leadership style can be characterized as a polite relationship with authority, based on personality. Leaders who pull people together are appreciated, since this generation believes in collective action (Al-Asfour and Lettau 2014). Responsible leadership is a relatively new field of research and seems to meet the demands of Millennials within an organizational environment. According to Doh and Quigley, the focus of responsible leadership is a leader's exchange with followers, team, organization, and society at large (Doh and Quigley 2014). Leadership in a global, complex, uncertain, and interconnected environment results in a need "to reduce complexity and uncertainty for people and provide a desirable future, which is shared by the people they lead. Leaders need to have a sense of purpose and a guiding vision, which help bundle individual and 'organizational energy"' (Maak and Pless 2006, p. 99). The new context, according to Maak and Pless, should affect the mindset, the roles and responsibilities of leaders, which "simultaneously change, become more complex and multi-faceted, expand from an internal leadership perspective to a broader world view, from a shareholder mindset to a stakeholder orientation with respect to the leadership role" (Ibid, p. 100). Contemporary leaders need to win the mandate to lead by using a relational leadership approach based on inclusion, collaboration, and co-operation with all stakeholder groups, including employees, clients and customers, business partners, the social and natural environment, and shareholders (Ibid, pp. 100-101). Responsible leadership may be best understood by using the metaphor of a weaver, where the responsible leader acts from the center, not the top, focusing more on building relationships than developing power (Ibid, p. 104). Maak and Pless show that a responsible leadership has these central value-based roles (Sarkar 2016, p. 10):

- Visionary: involving stakeholders in the process of future thinking,

- Steward: acting as a defender of the organization's most precious resources, including vision and relationships, 
- Servant: developing a vision that aligns with stakeholder needs and goals,

- Citizen: acting as integral part of the community which is committed not only to business matters but to civic matters,

- Coach: facilitating the relational process, development and learning,

- Architect: building a culture where diverse people find meaning, feel respected, recognized, and included,

- Storyteller and Meaning Enabler: creating shared systems of meaning, through sense making and dialogue,

- Change Agent: initiating change that will establish a value-conscious and sustainable business.

As Sarkar sums it up, responsible leadership combines the essential qualities of three well known leadership styles: transformational, servant, and authentic leadership. The transformational aspect of responsible leadership relates to encouraging teamwork, setting high performance targets, and encouraging out-of-the-box thinking among followers. As servants, responsible leaders "put the interests of subordinates first, over and above their own self interests. This creates an empowering experience for followers" (Ibid.). Empowerment leads to increased creativity at work, which is one of the most important factors of success in a VUCA world. Authenticity in a leader ensures learning agility, flexibility, and the participation of others, because the leader integrates diverse perspectives in decision making (Ibid.). Finally, Sarkar argues that the "all-inclusive leadership approach of responsible leadership is bound to make change management seamless" (Ibid, p. 11), and that building relationships can enhance employee performance and promote a democratic community for the benefit of an organization. The author finishes with a strong statement:

An individual's own self-reflection combined with an organization's vision, mission and practices also plays a major role in shaping the responsible leader who is selfaware, can subdue his/her self-interest for a greater cause and is committed to serving the broader interests of relevant stakeholders. Responsible leadership embraces societal issues and concerns based on sound ethical judgment, which ensures the long-term sustainability of any organization in the VUCA world.

\section{Mentoring}

While an appropriate leadership approach is helpful mid- and long-term, a mentoring approach could serve as a transitional solution to bridge the gap between Millennials and Baby Boomers because Millennials are very open to being mentored. As Ferri-Reed put it, in order to help Millennials succeed in the workplace one should "give them the big picture, help them find the 'me' in the team, and mentor them on career-building behaviors" (Ferri-Reed 2014, p. 18). Today, nearly all big companies have established mentoring programs that aim at developing a mentee through a personal relationship with a more experienced mentor (Biemann and Weckmüller 2014). In business, a 
mentor's task is usually to motivate one or more individuals to advance their careers by helping them to learn and work to their potential, and to find new perspectives and meaning in their jobs (Wells 1997). In many organizations a mentor is less likely to be an immediate supervisor, but may be found at a higher level or outside of the organization. Within a mentoring relationship, mentors provide their protégés with "sponsorship, exposure, and visibility, coaching, counseling, protection, friendship, and challenging assignments" (Bass and Bass 2008, p. 1092). Bass \& Bass add that mentors also act as role models and as a source of acceptance and confirmation. They may also increase the visibility of their protégé by informing other leaders about the young professional's great potential. Research on the topic shows that, in that way, mentoring provides both a psychosocial (acceptance, encouragement, coaching, counseling) and a careerfacilitation function (sponsorship, protection, challenging assignments, exposure, and visibility) (Yukl 2013). Although coaching is very often mentioned as a part of mentoring (which it is), there is a difference between coaching and mentoring. Clutterbeck suggests that "coaching in most applications addresses performance in some aspect of an individual's work or life; while mentoring is more often associated with much broader, holistic development and with career progress" (Clutterbuck 2008). Latest research also emphasizes that mentoring should be seen as reciprocal and collaborative, with benefits for mentors including job satisfaction, organizational commitment, and job performance (Ghosh and Reio 2013). Thus, mentoring is suggested as a tie that could help the generations to overcome their conflicts. By utilizing each generation's skills, mentoring brings the generations together. Kilber highlights that, perhaps unconsciously, these two generations may even seek each other out naturally, because many Baby Boomers have Generation Y children. Most Boomers report that Gen Y members look to them for advice and prefer them to Gen $\mathrm{X}$ colleagues as advisors (Kilber et al. 2014). Since building meaningful relationships is a basic human need, mentoring relationships could greatly increase the collaboration between generations for the benefit of organizations. As Neufeld shows, bonding is developed through a relationship where people are valued and unconditionally loved. Further, where there is bonding, a human being has no need to act rebelliously (Neufeld 2006). Thus, the first step towards unity between generations is the unconditional acceptance and appreciation of Gen Y members by Boomers. This can be a significant challenge because the expectations of the Millennials are difficult to meet. Since mentoring may typically have a negative connotation for Millennials, some authors even suggest labelling it differently - as career advising or organizational support (Kilber et al. 2014).

If one wants to go further, reverse mentoring may be a social exchange tool for keeping Boomers engaged and Millennials committed. Reverse mentoring is defined as mentoring of older employees by younger employees. Murphy states that the benefits of reverse mentoring include "building the leadership pipeline, fostering better intergenerational relationships, enhancing diversity initiatives, and driving innovation" (Murphy 2012, p. 550). The main focus of reverse mentoring is to help older generations acquire technological knowledge and to know how it can be used, for instance, to collaborate with customers or generate new contracts. Without reverse mentoring, this may be knowledge they would not acquire. Inevitably within this process, and this is where both organization and Boomers benefit, there will be 
occasions when seniors give feedback or advice to young associates, resulting in a mutual relationship. Furthermore, Millennials may come to identify with their mentees and even adopt some of their values and attitudes. Finally, reverse mentoring programs also result in higher retention of Millennials (Murphy 2012). This kind of mentoring has a double function: it increases Millennials' involvement within their organizations while at the same time engaging Baby Boomers.

\section{Conclusion and Further Research}

The VUCA world throws up challenges for contemporary organizations and highlights the conflict between senior leaders and Millennials. Strong discernment in intergenerational teams is needed to align organizations to a continuously changing world. The conflict between Baby Boomers and Millennials is a threat to organizations in the Western world. It hinders the parties involved from combining their strengths for the benefit of the organization. Humility and realistic self-evaluation are critical in order for members of both generations to work together in unity. This chapter is an attempt to increase understanding of the conflict by suggesting a leadership approach that could work for both generations and at the same time help organizations survive in a VUCA world. Leading Millennials is a challenge and, if we think of the characteristics of this generation, almost sounds like an oxymoron. But organizational success will only be achieved with Millennials and their strengths. Good relationships and appreciation are crucial to ensuring that responsible leadership and mentoring are successful. The era of typical hierarchical organizations with structures of power that demand military-type obedience are most likely over. Standardized approaches and norms no longer help in navigating VUCA contexts. Western leaders need to start dreaming, thinking, and trying new scenarios and approaches without knowing the outcome. This is the basic definition of playing. Leaders can only succeed if they are sufficiently humble to try things out and to fail within a safe environment. The new credo is: "I either win or learn." Sedlacek highlights that the world is not a chessboard with only limited opportunities for action (Sedlacek 2013). Instead, most of the strong and dynamic solutions will probably be found outside of the common playground. This is where Millennials can help, and this is also what many of them are excited about. The first step in making a joint effort is to overcome vanity on both sides and develop an authentic appreciation of each other.

Acknowledgment I would like to thank Kay Caldwell for her help with the language editing of this chapter. 


\section{Bibliography}

Al-Asfour A, Lettau L (2014) Strategies for leadership styles for multigenerational workforce. J Leadersh Account Ethics 11:58-69

Balda JB, Mora F (2011) Adapting leadership theory and practice for the networked, millennial generation. J Leadersh Stud 5:13-24

Bass BM, Bass R (2008) The bass handbook of leadership: theory, research, and managerial applications, 4th edn. Free Press, New York

Bencsik A, Tímea J, Horváth-Csikós G (2016) Y and Z generations at workplaces. J Compet 8 (3):90-106

Biemann T, Weckmüller H (2014) Mentoring: wann nützt es und wem nützt es? Pers Q 66(2):46-49

Bishop WH (2014) Structure? We don't need no stinkin' structure! J Strateg Leadersh 5:48-58

Christensen S (2017) Millennials rewrite workplace rules. Signal 71(9):13

Clutterbuck D (2008) What's happening in coaching and mentoring? And what is the difference between them? Dev Learn Organ 22(4):8-10. https://doi.org/10.1108/14777280810886364

DelCampo RG, Haggerty LA, Knippel MJA (2011) Managing the multi-generational workforce. Taylor \& Francis, Farnham

Doh JP, Quigley NR (2014) Responsible leadership and stakeholder management: influence pathways and organizational outcomes. Acad Manag Perspect 28(3):255-274

Ferri-Reed J (2014) Millennializing the workplace. J Qual Particip 37(1):13-14

Gelbart N, Komninos J (2012) Who? where? Y? Charter J 84(7):20-23

Gesell I (2010) How to lead when the generation gap becomes your everyday reality. J Qual Particip 32(4):21-24

Ghosh R, Reio TG Jr (2013) Career benefits associated with mentoring for mentors: a metaanalysis. J Vocat Behav 83(1):106-116. https://doi.org/10.1016/j.jvb.2013.03.011

Goleman D, Boyatzis RE, McKee A (2004) Primal leadership: learning to lead with emotional intelligence. Harvard Business School Press, Boston, pp 253-256

Hall A (2016) Exploring the workplace communication preferences of millennials. J Org Cult Commun Confl 20:35-44

Hines A (2011) A dozen surprises about the future of work. Employ Relat Today 38:1-15

Horney N, Pasmore B, O'Shea T (2010) Leadership agility: a business imperative for a VUCA world. Hum Resour Plan 33(4):32-38

Huffington Post (2011) Boomers vs. generation Y: bridging the generation gap at the office. Retrieved from http://www.huffingtonpost.com/2011/11/18/bridging-the-generation-gap_n_ 1102396.html

Jumpertz S (2017) Chancen für Jung Manager. managerSeminare 231:8

Keese C (2016) Silicon Valley: Was aus dem mächtigsten Tal der Welt auf uns zukommt. Penguin, Munich

Kilber J, Barclay A, Ohmer D (2014) Seven tips for managing generation Y. J Manag Policy Prac 15(4):80-91

Lissitsa S, Kol O (2016) Generation X vs. generation Y - a decade of online shopping. J Retail Consum Serv 31:304-312

Maak T, Pless NM (2006) Responsible leadership in a stakeholder society: a relational perspective. J Bus Ethics 66(1):99-115

Müller EB (2013) Innovative leadership: Die fünf wichtigsten Führungstechniken der Zukunft. Haufe Verlag, Freiburg

Murphy W (2012) Reverse mentoring at work: fostering cross-generational learning and developing millennial leaders. Hum Resour Manag 51(4):549-573

Neufeld G (2006) Hold on to your kids: why parents need to matter more than peers. Ballantine Books, New York

Pinzaru F, Vatamanescu E-M, Mitan A (2016) Millennials at work: investigating the specificity of generation Y versus other generations. Manag Dyn Knowl Econ 4(2):173-192 
PwC (2011) Millennials at work: reshaping the workplace. https://www.pwc.com/en_M1/m1/ services/consulting/documents/ millennials-at-work.pdf. Accessed 23 May 2017

Rodriguez A, Rodriguez Y (2015) Metaphors for today's leadership: VUCA world, millennial and 'cloud leaders'. J Manag Dev 34(7):854-866

Sarkar A (2016) We live in a VUCA world: the importance of responsible leadership. Dev Learn Organ 30(3):9-12

Sedlacek T (2013) Die Ökonomie von Gut und Böse. Munich, Goldmann

Swaim R (2016) Peter Drucker on leading millennials. Retrieved from https://www. managementmattersnetwork.com/strategic-leadership/columns/peter-drucker-on-leadingmillennials

Tapscott D (2009) Grown up digital, now the net generation is changing your world. McGraw-Hill, New York

Traüffer HCV (2008) Towards an understanding of discernment: A 21st-century model of decision making. Doktoral Dissertation, Regent University Virginia Beach, VA. Published at Proquest LLC. UMI-No: 3325539

Wells S (1997) From sage to artisan: the nine roles of the value-driven leader. David-Black Publishing, British Columbia

Yukl G (2013) Leadership in organizations. Pearson Education Limited, Harlow

Johann Kornelsen is managing partner of 3 D Leaders, a European HR-consulting and headhunting network, and the co-owner and CEO of an investment company that invests in ecommerce-based businesses. His pioneering networking approach in Germany connects Christian entrepreneurs and investors with the aim of developing a new generation of generous entrepreneurs for the benefit of society. Previously, he worked in strategic development as the assistant to the president of a private university and was founder and CEO of a consulting company with a focus on HR development. Having finished his MA in strategic management in Germany in 2011, Johann is currently finishing his Ph.D. dissertation at Regent University (USA). His topic is organizational leadership, focusing on entrepreneurship and leadership education through mentoring. Passionate about pioneering and networking, Johann enjoys traveling for business and voluntary work, connecting people in new initiatives, and speaking at international conferences about issues of organizational leadership and leadership development. Johann and Helena Kornelsen have been married since 2003 and have two sons aged 12 and 8.

Open Access This chapter is licensed under the terms of the Creative Commons Attribution 4.0 International License (http://creativecommons.org/licenses/by/4.0/), which permits use, sharing, adaptation, distribution and reproduction in any medium or format, as long as you give appropriate credit to the original author(s) and the source, provide a link to the Creative Commons licence and indicate if changes were made.

The images or other third party material in this chapter are included in the chapter's Creative Commons licence, unless indicated otherwise in a credit line to the material. If material is not included in the chapter's Creative Commons licence and your intended use is not permitted by statutory regulation or exceeds the permitted use, you will need to obtain permission directly from the copyright holder.

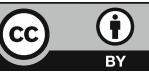

